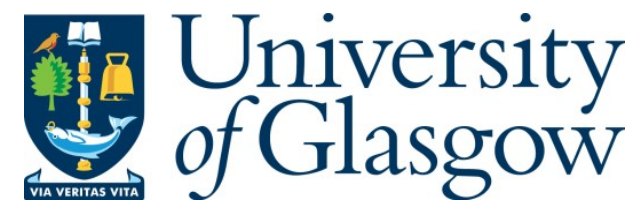

Kontis, K., Lada, C., and Zare-Behtash, H. (2008) Effect of dimples on glancing shock wave turbulent boundary layer interactions. Shock Waves, 17 (5). pp. 323335. ISSN 0938-1287

Copyright (C) 2007 Springer-Verlag

A copy can be downloaded for personal non-commercial research or study, without prior permission or charge

Content must not be changed in any way or reproduced in any format or medium without the formal permission of the copyright holder(s)

When referring to this work, full bibliographic details must be given

http://eprints.gla.ac.uk/84665

Deposited on: 18 June 2014

Enlighten - Research publications by members of the University of Glasgow http://eprints.gla.ac.uk 


\title{
Effect of Dimples on Glancing Shock Wave Turbulent Boundary Layer Interactions
}

\author{
K. Kontis, C. Lada, H. Zare-Behtash \\ University of Manchester, School of MACE, Manchester, M60 1QD, UK
}

\begin{abstract}
An experimental study has been conducted to examine the control effectiveness of dimples on the glancing shock wave turbulent boundary layer interaction produced by a series of hemi - cylindrically blunted fins at Mach numbers 0.8 and 1.4, and at angles of sweep $0^{\circ}, 15^{\circ}, 30^{\circ}$ and $45^{\circ}$. Schlieren photography, oil flow, pressure sensitive paints, and pressure tappings were employed to examine the characteristics of the induced flow field. The passive control technique used a series of $2 \mathrm{~mm}$ diameter, 1 mm deep indents drilled across the hemi-cylindrical leading edge at angles $0^{\circ}, 45^{\circ}$ and $90^{\circ}$. The effects of dimples were highly dependent on their orientation relative to the leading edge apex, and the local boundary layer properties.
\end{abstract}

Keywords: dimples, passive flow control, pressure sensitive paints, transonic and supersonic flows

\section{Introduction}

The shock wave boundary layer interaction is both undesirable and unavoidable. The effect of boundary layer separation, due to strong shock waves, can distort the quality of airflow in engines inlets, reduce th effectiveness of control surfaces, and have a detrimental effect on the efficiency of lifting surfaces [1,2]. Boundary layer reattachment can produce intense local heating and excessive pressure loads, which are also undesirable $[3,4]$. Shock wave boundary layer interaction plays a critical role in the design of wing and tail-plane junctions with the fuselage, supersonic engine inlets and deflected control surfaces of transonic and supersonic vehicles. Glancing interaction occurs when the shock generator is mounted normal to the supporting surfaces of the wind tunnel. The leading edge of the shock generator can be varied in a number of ways; it can be sharp or blunt, swept or unswept. The shock wave generated 'glances' across the boundary layer developing on the adjoining surface. Experimental investigations into 
glancing shock wave turbulent boundary layers have been extensively carried out during the past 60 years $[5,6]$. A significant review paper by Panaras [7] summarized the gradual progress in the understanding of the nature of the induced flow field and also identified issues that require further research. Delery [8] in his review paper first considered some fundamental properties of the interaction for a two dimensional adiabatic flow developing on a flat surface, examined the flow features of the interaction process and finally presented the methods that were used to control the shock wave boundary layer interaction, classifying them into two categories; those acting on the boundary layer properties before it enters the shock region and those having a local action in the shock foot region itself.

Barnhart [9] performed a series of experiments to investigate the effects of Mach number variation on the characteristics of the unsteady shock wave/turbulent boundary layer interaction generated by a blunt fin. A single blunt fin with a hemi-cylindrical leading edge was used in all experiments at Mach numbers from 2.0 to 5.0. The measurements in that investigation included surface flow visualization, and static and dynamic pressure measurements, both on-centreline and off-centreline of the blunt fin axis. As the Mach number increased, the separation line was located further upstream of the blunt fin and the lateral extent of the separated region was also seen to increase. The separation line formed an arced trace, sweeping back around the blunt fin leading edge. The static pressure measurements confirmed the observations on the extent of the interaction found from the surface flow visualisation experiments.

Hussain [10] studied glancing shock waves on blunt fins at Mach number 2.4 and among other things, the effect the sweep angle from $30^{\circ}$ to $80^{\circ}$ had to the interaction. He observed that the effect of leading edge sweep was a substantial decline in the scale of the interaction on both the fin surface and the sideconnecting wall. Kubota [11] observed a system of counter rotating vortices present in the interaction region, and he postulated the number and strength of theses vortices depended on the bluntness, incidence and sweep angle. He also identified that three - dimensional interaction regions, brought about by oblique shock wave glancing across a turbulent boundary layer consists of two distinct viscous layers: a) the sidewall boundary layer growing along the flat surface; and b) the induced layer originating on the shockgenerator surface near the root, which crosses the path of the side wall boundary layer. Squire [12] showed that correlations between swept and unswept normal shock interactions could be made in terms of 
the local Mach number, and thus shock angles and heights measured from flow visualizations are not always functions of free stream Mach number alone. For swept wings, leading edge separation resulted in a strong vortex flow inbound of the edge. The conditions for the onset of separation correlated in terms of Mach number and incidence normal to the edge. Raju et.al. [13] documented the three-dimensional pressure field resulting from blunt fin induced turbulent-shock boundary layer interactions at a freestream Mach number of 1.8 using the Pressure Sensitive Paint (PSP) technique. Detailed comparisons of the PSP results with conventional static pressure port measurements showed generally excellent agreement both along the symmetry plane and in the spanwise direction.

Chokani [14] showed that under transonic conditions, passive control in the form of porous surface in the region of the shock wave / turbulent boundary layer interaction weakens the pressure rise through the interaction. The more gradual pressure rise was seen to produce a weaker shock wave with beneficial drag reductions. There was also a presence of a thin shear layer over the porous surface that was independent of the boundary layer. That shear layer altered the effective surface geometry in the interaction region, which provided the mechanism for weakening the shock wave. That observation suggested that the shockinduced separation might be delayed or reduced. The presence of the shear layer did however also appeared to increase the skin friction penalties. McConnel [15] studied the effect of roughness on the boundary layer profiles. She showed that both increasing roughness height and roughness distribution before the interaction caused a thicker boundary layer and slower near-wall velocities, resulting in a less full boundary layer. The higher Mach number caused roughness to have a greater effect on the profiles. Babinsky et. al. [16] performed a series of experiments to study the effects of roughness in certain combinations of rough and smooth surfaces on an incipient shock wave / turbulent boundary layer interaction at $\mathrm{M}=2.5$ for two shock strengths below incipient separation. They found no sign of any largescale separation, even for a surface covered throughout with the largest roughness tested. Babinsky and Edwards [17], who investigated the influence of a region of roughness upstream of an interaction, found that while the effects of roughness on the boundary layer profile persisted far downstream, the shock/ boundary layer interaction was only marginally affected. In contrast, other studies for example by Disimile and Scaggs [18], Inger [19] and Holden [20] who studied a variety of supersonic and hypersonic 
flow configurations found that roughness was capable of inducing large scale flow separation in cases where the equivalent smooth wall flow remained attached.

Therefore, the literature survey indicated that studies are still required to shed further light into the fundamental physics associated with glancing shock boundary layer interactions, especially with the presence of surface roughness in the transonic and supersonic regime. In the present investigation, the control effectiveness of dimples on the glancing shock wave turbulent boundary layer interaction produced by a series of hemi - cylindrically blunted fins at Mach numbers 0.8 and 1.4 , and at a range of angles of sweep was investigated. The chosen experimental set-up aims to provide data for further CFD validation. The applicability of Pressure Sensitive Paints for the surface flow mapping of junction flows was also examined.

\section{Experimental Set-up and Models Description}

The experiments were performed in a closed-return supersonic wind tunnel facility with a rectangular cross section of $100 \mathrm{~mm}$ in height, $26 \mathrm{~mm}$ in width and $200 \mathrm{~mm}$ in length, at Mach numbers, $\mathrm{M}=0.8$ and 1.4 and Reynolds numbers, $\operatorname{Re}=6.25 \times 10^{5}$ and $1.09 \times 10^{6}$ respectively (based on the free-stream velocity and the chord-length of the fin at the root). The incidence was kept constant to $0^{\circ}$. The models used are shown in Fig. 1. All models incorporated a hemi-cylindrical leading edge and had a uniform thickness of $6 \mathrm{~mm}$. Four different sweep angles were employed i.e. $0^{\circ}, 15^{\circ}, 30^{\circ}$ and $45^{\circ}$. For the $0^{\circ}$ sweep case, the chord-length was $34 \mathrm{~mm}$ and the span was $26 \mathrm{~mm}$. A series of $2 \mathrm{~mm}$ diameter, $1 \mathrm{~mm}$ deep and $3 \mathrm{~mm}$ spaced dimples were drilled across the hemi-cylindrical leading edge at angles $0^{\circ}, 45^{\circ}$ and $90^{\circ}$ relative to the tip of the leading edge. The distance of the dimple from the side wall was $1.5 \mathrm{~mm}$. The model blockage ratio was $8 \%$. The boundary layer on the adjoining wall was turbulent and its thickness at the fin leading edge level was $2 \mathrm{~mm}$ and $5.5 \mathrm{~mm}$ for $\mathrm{M}=0.8$ and 1.4 respectively.

High-speed schlieren photography was employed to study the flow field features around the fins in a standard Z-type optical arrangement. The light source was a 625 ns duration, 5 joules argon stabilized pulsed flash system equipped with a $90 \mathrm{~mm}$ focal length convex lenses. The images were recorded on a PC via a CCD camera connected to a video grabber. The experiments were carried out in dark conditions. 
PC equipped with a high speed Data Acquisition System (DAQ) was used to trigger the light source and the camera. The pressure distribution along the adjoining sidewall was measured at discrete points using 25 pressure tappings of $1 \mathrm{~mm}$ diameter. Fig. 2 shows the location of the pressure tappings. The pressure at each point was recorded by individual absolute pressure transducers (SenSym part no. ASDX015 with a range 0 to $15 \mathrm{psi}$ ) connected to the $\mathrm{PC}$ via an $\mathrm{ADC}$ board. The pressure uncertainty in the transducer data was $3 \%$. The pressure tapping data, in the present article, is presented in the form of Tecplotgenerated two-dimensional pressure maps. Oil flow technique was employed to visualise the surface flow on the blunted fins and the side wall, using a mixture of titanium dioxide, linseed and silicon oil [21].

The in-house developed intensity based Pressure Sensitive Paint (PSP) technique was used to map the pressure distribution on the adjoining side-wall [22]. The PSP consists of a dispersion of luminescent probe molecules in an oxygen permeable binder layer. An excitation light source of wavelength $\lambda_{\mathrm{e}}$ and intensity $I_{e}$ is used to promote molecules to an excited energy state [23-25]. For PSP, there are two desirable mechanisms for the molecule to return to the ground state: luminescence at a wavelength $\lambda$ and intensity I or the transfer of energy by collision with an oxygen molecule, a process called oxygen quenching [26-28]. For a given excitation level, the emitted light intensity varies inversely with the local oxygen partial pressure, and thus air pressure, since oxygen is a fixed mole fraction of air. The luminescent intensity, I, is related to oxygen concentration, by the Stern-Volmer equation,

$\frac{I_{O}}{I}=1+\left[O_{2}\right] \times K_{S V}(T)$

The partial pressure of oxygen, in air, is $21 \%$ of the air pressure. $\mathrm{I}_{\mathrm{o}}$ is the luminescent intensity when oxygen concentration is zero, $\left[\mathrm{O}_{2}\right]$ is the oxygen concentration, $\mathrm{T}$ is the temperature, and $\mathrm{K}_{\mathrm{sv}}$ is the SternVolmer constant. Therefore Eq. (1) can be expressed in terms of air pressure, P, as follows,

$\frac{I_{O}}{I}=1+0.21 \times P \times S \times K_{S V}(T)$

Let $\mathrm{K}=0.21 \mathrm{~K}_{\mathrm{sv}} \mathrm{S}$, where $\mathrm{S}$ is the Herny's solubility constant, then Eq. (2) can be simplified to,

$\frac{I_{O}}{I}=1+P \times K(T)$

For wind tunnel testing, Eq. (3) is usually normalized by the luminescent intensity, $I_{\text {ref, at a known }}$ constant reference pressure, $\mathrm{P}_{\text {ref, }}$ under wind-off conditions. Therefore the Stern-Volmer relation can be 
adapted for aerodynamic testing to,

$\frac{I_{r e f}}{I}=A(T)+B(T)\left(\frac{P}{P_{r e f}}\right)$

where $A(T)=\frac{1}{1+K(T) P_{r e f}}$ and $B(T)=\frac{K(T) P_{r e f}}{1+K(T) P_{r e f}}$

$I_{0}$ has been eliminated from Eq. (4), making the effects of paint thickness and luminophore concentration to be eliminated by the rationing procedure. A more general expression is as follows,

$\frac{I_{r e f}}{I}=A(T)+B(T)\left(\frac{P}{P_{r e f}}\right)+C(T)\left(\frac{P}{P_{r e f}}\right)^{2}+\ldots$

Coefficients $\mathrm{A}, \mathrm{B}$ and $\mathrm{C}$ can be determined by static calibration tests.

Bathophenanthroline Ruthenium dye was selected to make the paint. Its peak excitation occurs at a wavelength of $478 \mathrm{~nm}$ and the maximum emission takes place at a wavelength of $678 \mathrm{~nm}$. The main components of the intensity PSP system are: a JVC TK-1280E CCD camera, a continuous $300 \mathrm{~W}$ Xenon light source system, a $458 \mathrm{~nm}$ narrow band pass interference filter to select the appropriate excitation wavelength for the paint used, a heat absorbing glass to reduce the amount of heat transmitted through the optical system and a $665 \mathrm{~nm}$ long pass optical filter to allow only light transmitted by the paint to be recorded by the CCD camera. The PSP paint was calibrated using a pressure- and temperature-digitally controlled chamber. The pressure and temperature dependence of the luminescence intensity curve is shown in Fig. 3. In the present study, the temperature during the experiments was assumed constant and the calibration curve corresponding to $290 \mathrm{~K}$ (see Fig. 3) was employed to determine the calibration coefficients in Eq. (6). Figure 4 depicts the schematic of the optical set-up used in the experiments.

The accuracy of intensity-based pressure-sensitive-paint optical systems is sensitive to drift and ageing of the light source and detector as well as paint in-homogeneities in dye concentration and film thickness. The ratio of wind-on image to wind-off image is processed to eliminate the effects of these factors. However, the effect of the variation of illumination is not cancelled. Aging is another potential source of error but all tests were completed within few hours. Because the models used were simple in shape and the aerodynamic loads were small, model deflection was negligible. The accuracy of the technique corresponds to that of the thermocouples and pressure transducers used for calibration, which is in the 
range of $\pm 2.5 \mathrm{~K}$ and $\pm 250 \mathrm{~Pa}$, depending on the absolute temperature and pressure, respectively. Calibration uncertainty also comes from curve fitting the data to Eq. (6) and non-uniformity of the calibration constants. The confidence interval of the calibration curves was estimated to be $97 \%$. With the large signal levels from the dye, the major limit to precision of the pressure is the detector noise, which is $3 \%$ percent. The spatial resolution of the technique depends on the minimum pixel size, which can be resolved by the CCD camera. In the present study, it is equivalent to a square of side length $0.0001 \mathrm{~m}$ (or $0.1 \mathrm{~mm})$. Prior to the collection of the fluorescent images for analysis, a pixel-to-pixel correspondence between the images, projected onto the CCD camera, was conducted. The spatial intensity response of the camera was also established. Fig. 5 shows some representative comparisons, in the stream-wise direction, of PSP results with the discrete measurements of pressure tappings located in numbers 13, 17, 18, 20, 23 (lower side) 37, 42, 47 (upper side), (Fig. 2 shows the location of the pressure tappings on the side plate). From the comparisons with the pressure transducer data, and the associated errors related to the calibration procedure, detector noise and effect of illumination non-uniformities, the overall pressure uncertainty in the PSP results was 5\%.

\section{Results and Discussion}

\subsection{Effect of dimples on shock wave / boundary layer interaction at $0^{\circ}$ leading edge sweep}

Figures $6 \mathrm{a}, 6 \mathrm{~b}, 7 \mathrm{a}, 7 \mathrm{~b}, 8 \mathrm{a}$ and $8 \mathrm{~b}$ show the effect of dimples, located at $45^{\circ}$ degrees across the hemicylindrical leading edge, for the $0^{\circ}$ angle of sweep at $\mathrm{M}=0.8$. As the flow approaching the blunt leading edge decelerates and reaches a stagnation condition. Then it further expands near the corner encompassing expansion waves. Later it terminates through a shock wave. There is also a stand-off shock of the fin parallel to the leading edge. For the no-dimples case, the flow field is symmetrical, Fig. 8a. The dimples affect the local flow field around the leading edge. They induce adverse pressure gradients due to the local surface roughening causing the thickening of the boundary layer. As a result, the dimples alter the effective geometry at the leading edge region. However, due to their location, their effect is not symmetrical, Fig. 8 b. On the lower side, a normal shock wave is observed at approximately the one-third of the chord-length of the fin. Its occurrence is associated to the asymmetric alteration of the effective 
geometry due to dimples causing different levels of bluntness between the upper and lower sections of the hemi-cylindrical leading edge. As a result, the expansion of the flow near the corner between the lower and upper sides has to be different. This is clearly evident in Figs. 5 and 8b, where the drop in pressure in the lower side along the generator is higher than that in the upper side. Therefore, a normal shock wave is formed to raise the pressure. It is also conjectured that the oncoming Mach number (on the lower side) drops quickly, at some distance from the surface, to a value where it is longer possible to achieve the required pressure jump (flow deflection) across a weak oblique shock wave and the flow downstream turns subsonic. This means that it is not possible for a lamda-shock structure to exist (the front shock leg curves upstream to form a normal shock which becomes effectively the main shock). Presence of the dimples prevents the shock from moving too far downstream, which may lead to reduced shock motion and delay of buffet onset. The normal shock wave interacts with the fin boundary layer forcing it to separate. On the upper side, the oblique shock wave strengthens, Fig. $8 b$, increasing the scale of interaction. The above observations are supported by the PSP maps on the side-wall shown in Figs. 6a and 6b. Analysis of PSP pattern along the generator (parallel to the fin surface), Fig. 5, shows expansion of flow through a gradual drop in pressure. The pressure raises again through a shockwave. For the case with the dimples, on the lower section, a strong interaction region is mapped near the apex of the fin corresponding to the location of the normal shock wave shown in Fig. 8b.

Figures $7 \mathrm{a}$ and $7 \mathrm{~b}$ display the surface flow features associated with the effect of dimples. For the nodimple case, there is evidence of at least three separation lines and two attachment lines on the side wall. The surface patterns in the plane of symmetry ahead of the fin apex are characterized by a well defined primary separation line (S1) followed by a distinct nodal point of attachment (N.P.A.), Fig. 7a. The attachment line A1 emerges from the nodal point and moves outboard and downstream. The primary (S1) and secondary (S2) separation lines initially run parallel to the fin surface some distance downstream of the fin apex suggesting negligible lateral pressure gradients in that region. However, at approximately the one-third of the chord-length a slight kink in the steam-lines is observed on the upper and lower sections of the sidewall forcing them to change direction symmetrically suggesting strong lateral pressure gradients in that region. The kinks are due to the presence of the terminating shock waves observed in 
Fig. 8a. Between the secondary separation line and the fin apex, there is the attachment line A2 which follows around the fin shoulder. Tertiary separation line (S3) emerges downstream of the fin apex and it is inclined to the fin surface. Figure 9 shows the schematic of the observed surface streak pattern and flow field based on Hussain's [10] model for an unswept blunt fin. It comprises of a series of counter rotating vortices upstream of the fin associated with S1, S2, A1 and A2 due to the shock wave and fin induced separation, and another pair near the fin root associated with S3.

The introduction of dimples brings about an increase in the scale of the interaction, as seen comparing Figs. $7 \mathrm{a}$ and $7 \mathrm{~b}$, however their effect is not symmetrical. Three more separation lines are observed on the side wall. Separations lines S4 and S5 emerge on the upper section of the wall inclined to the fin surface. Separation line S6 is observed on the lower section of the wall due to presence of the normal shock wave shown in Fig. 8b. The primary separation (S1) distance ahead of the fin apex remains constant, however, the lateral extent of the interaction increases. On the upper section, the primary (S1) and secondary (S2) separation lines initially run parallel to the fin surface some distance downstream of the fin apex. However, at approximately the half of the chord-length, a kink in the steam-lines is observed forcing them to change direction. The kink is due to the presence of the shock wave observed in Fig. $8 \mathrm{~b}$. On the lower section, at approximately the one-third of the chord-length, a strong kink in the steam-lines is observed. The location of the kink corresponds to separation line S6 and is due to the presence of the normal shock wave observed in Fig. 8b. The tertiary separation lines seen right near the expansion corner are due to the pair of counter rotating vortices near the fin root. On the lower section, the tertiary separation line interacts with S6. As it has been explained in the discussion above, for the cases with and without dimples, the terminating shock effect is seen on the side wall. Moreover, the interaction of the terminating shock wave with the boundary layer on the surface may lead to lambda type shock pattern; but the width of lambda will be small.

Figure 10 shows the effect of dimples, located at $45^{\circ}$ degrees across the hemi-cylindrical leading edge, for the $0^{\circ}$ angle of sweep at $M=1.4$. For the no-dimples case, the shock wave system is symmetrical, Fig. 10a. The dimples affect the local flow field around the leading edge and their effect is not symmetrical, Fig. 10b. However, in comparison with the $\mathrm{M}=0.8$ case, their control effectiveness and influence in the flow 
field characteristics is different. For the $M=1.4$ case, the boundary layer is thicker (see Section 2). It is conjectured that the mechanism of interaction is highly dependent on the local boundary layer thickness and properties at the fin leading edge and the side wall, which play a vital role in the extent of shock induced separation region. Further studies are required to examine in detail the fundamental flow physics, and control effectiveness of different dimple geometries. On the lower side, the terminating shock wave increases in strength. Again this is associated to the asymmetric alteration of the effective geometry due to dimples causing different levels of bluntness between the upper and lower sections of the hemicylindrical leading edge. The shockwave interacts with the fin boundary layer causing it to separate. On the upper side, the scale of the interaction increases in size due to the strengthening of the oblique shock wave, Fig. 10b. The above observations are also supported by the PSP maps and pressure tapping measurements.

Figures 11a and 11b display the surface flow features associated with the effect of dimples at $\mathrm{M}=1.4$. For the no-dimples case, Fig. 11a, the flow pattern is similar to that observed in the $M=0.8$ case, see Fig. 7 a. The primary (S1) and secondary (S2) separation lines initially run parallel to the fin surface some distance downstream of the fin apex suggesting negligible lateral pressure gradients in that region. However, at approximately the two-thirds of the chord-length, a kink in the steam-lines is observed in the upper and lower sections of the sidewall forcing them to change direction symmetrically. The kinks are due to the presence of the symmetric shockwave observed in Fig. 10a.

The introduction of dimples brings about an increase in the scale of the interaction, as seen comparing Figs. 11a and $11 \mathrm{~b}$, however their effect is not symmetrical. In comparison to the $\mathrm{M}=0.8$ case with dimples, no more separation lines are observed on the side wall. On the lower section, the primary (S1) and secondary (S2) separation lines initially run parallel to the fin surface some distance downstream of the fin apex. However, at approximately the two-thirds of the chord-length, a kink in the steam-lines is observed forcing them to change direction. The kink is due to the presence of the shock wave observed in Fig. 10b. On the upper section, at approximately the middle of the chord-length, a strong kink in the steam-lines is observed. At approximately the two-thirds of the chord-length, a small separated region is observed at the root of the fin with the side wall, which is due to the strong shock, observed Fig. 10b, 
causing the separation of the side wall boundary layer.

\subsection{Effect of dimples orientation on shock wave / boundary layer interaction}

Figures 6(a-d), 7(a-d) and 8(a-d) show the effect of dimples orientation on shock wave boundary layer interaction for the $0^{\circ}$ angle of sweep at $\mathrm{M}=0.8$. For the case with the dimples located at $0^{\circ}$ degrees across the hemi-cylindrical leading edge, their presence causes the thickening of the fin boundary layer and the alteration of the effective geometry at the leading edge region. Their effect on the upper and lower sides is symmetrical. By comparing Figs. 8a and 8c, although the shockwave remains constant, its strength decreases. This causes a less intense shock boundary layer interaction both on the fin surface and the upper section of the side wall, raising the pressure to a much lower value than that observed for the dimples located at $45^{\circ}$ degrees across the hemi-cylindrical leading edge. The above observations are supported by the PSP maps on the side-wall shown in Figs. 6a and 6c, and the pressure variations along the generator (parallel to the fin surface) on the upper surface, shown in Fig. 5. The symmetry of the induced interaction is also observed in the surface flow patterns shown in Figs. 7a and 7c. In comparison with the no-dimples case, the number of the observed separation and attachment lines remains constant. Although the size of the interaction remains the same, the observed flow events are much more pronounced. For example, the separation line (S3) is now clearly seen together with the vortical flow structure at the root of the fin on both the upper and lower sides.

For the case with the dimples located at $90^{\circ}$ degrees across the hemi-cylindrical leading edge, their effect on the upper and lower sides is not symmetrical, Figs. 8a and 8d. On the lower side, the scale of the interaction increases, however the shockwave raises surface pressure to similar values to those measured for the case with the dimples located at $45^{\circ}$ degrees across the hemi-cylindrical leading edge, Fig. $8 \mathrm{~b}$. Presence of the dimples prevents the shock from moving too far downstream. On the upper side, the scale of interaction increases and the shockwave strengthens, Fig. 8d, raising surface pressure to much higher values to those measured for the case with the dimples located at $45^{\circ}$ degrees across the hemi-cylindrical leading edge. The above observations are supported by the PSP maps on the side-wall shown in Figs. 6a and $6 \mathrm{~d}$, and pressure variations along the generator shown in Fig. 5. The surface flow patterns of the 
induced interactions are shown in Figs. $7 \mathrm{a}$ and $7 \mathrm{~d}$. In comparison with the no-dimples case, one more separation line (S4) is observed on the bottom section of the side wall inclined to the fin surface and the size of the interaction increases. On the upper section, the primary (S1) and secondary (S2) separation lines initially run parallel to the fin surface some distance downstream of the fin apex. However, at approximately the one third of the chord-length, a slight kink in the steam-lines is observed forcing them to change direction. The kink is due to the presence of the shock wave observed in Fig. 8d. On the lower section, at approximately the half of the chord-length, a strong kink in the steam-lines is observed. The location of the kink is due to the presence of the shock wave observed in Fig. 8d.

\subsection{Effect of angle of sweep on shock wave / boundary layer interaction with and without dimples}

A substantial decline in the scale of interaction, and an overall increase of the intensity of the pressure levels in the whole interaction region on the side-connecting wall were observed with increasing leading edge sweep. This is evident for example in the Tecplot pressure maps of the transducer data for the nodimples case at $\mathrm{M}=1.4$, Figs. $12 \mathrm{a}$ and $12 \mathrm{~b}$, and the PSP maps for the case with the dimples located at $45^{\circ}$ degrees across the hemi-cylindrical leading edge at $M=0.8$, Figs. $6 a$ and 6 e. The results from the schlieren pictures are inconclusive for the non-zero sweep cases, as the flow field captured by the camera is the integrated effect of the flow on the fin surface, and therefore no comparisons can be drawn.

Figures $7 \mathrm{~b}$ and $7 \mathrm{e}$ display the surface flow features associated with the effect of leading edge sweep for the case with the dimples located at $45^{\circ}$ degrees across the hemi-cylindrical leading edge at $\mathrm{M}=0.8$. Increasing the leading edge sweep from $0^{\circ}$ to $15^{\circ}$ brings about a decline in the scale of the interaction, as seen comparing Figs. $7 \mathrm{~b}$ and $7 \mathrm{e}$. The stand off distance at the apex is also observed to decrease steadily with increasing sweep. The flow patterns in Fig. 7e do not show the separation lines S4, S5 and S6 observed in the $0^{\circ}$ leading edge sweep case, Fig. $7 \mathrm{~b}$. The primary separation (S1) distance ahead of the fin apex undergoes a small decline with increasing sweep, and the lateral extent of the interaction decreases. On the upper section of the sidewall, the primary (S1) and secondary (S2) separation lines tend to run parallel to the fin surface as no kink was observed due to the attenuation of the strength of the shock wave in that section. On the lower section of the sidewall, the separation line S6 is not present and the kink is 
smoother. However, two additional separation lines, S4 and S5, are observed in the lower section, emerging at approximately the one-third of the chord-length and two-thirds of the chord-length respectively, downstream of the fin apex, inclined to the fin surface, Fig. 7e. Similar effects were observed for the case with the dimples located at $45^{\circ}$ degrees across the hemi-cylindrical leading edge at $\mathrm{M}=1.4$ and $0^{\circ}$ incidence. In comparison to the $\mathrm{M}=0.8$ cases, the effect of sweep is more pronounce at $\mathrm{M}=1.4$ in terms of its effect on stand-off at the apex and scale of interaction. The results are in good agreement with Hussain [10].

\section{Conclusions}

The dimples affect the local flow field around the leading edge and alter the effective geometry at the leading edge region. The mechanism of interaction is highly dependent on the local boundary layer thickness and properties at the fin leading edge and the side wall, which play a vital role in the extent of shock induced separation region. The further studies are required to examine in detail the fundamental flow physics, and the control effectiveness of different dimple geometries. Their effect on shock boundary layer interaction is highly dependent on the orientation relative to the leading edge apex. For the cases with the dimples located at $90^{\circ}$ and $45^{\circ}$ degrees across the hemi-cylindrical leading edge, their effect is not symmetrical. On the upper side, the oblique shock strengthens, increasing the scale of the interaction. On the lower side, the shock wave dramatically alters both in size and shape to that observed for the no-dimple case. Presence of the dimples prevents the shock from moving too far downstream, which may lead to reduced shock motion and delay of buffet onset. For the $90^{\circ}$ degrees orientation case, in comparison with the no-dimples case, one more separation line (S4) is observed on the bottom section of the side wall inclined to the fin surface. For the $45^{\circ}$ degrees orientation case, in comparison with the no-dimples case, three more separation lines are observed on the side wall inclined to the fin surface. For the $0^{\circ}$ degrees orientation case, in comparison with the no-dimples case, the number of the observed separation and attachment lines remains constant and the size of the interaction remains the same. However, the observed flow events are much more pronounced. The presence and location of the observed kinks in the surface steam-lines is related to the shock wave system present in the upper and 
lower sides of the fin. Their presence forces the separation lines to change direction suggesting strong lateral pressure gradients in that region. A substantial decline in the scale of interaction, and an overall increase of the intensity of the pressure levels in the whole interaction region on the side-connecting wall were observed with increasing leading edge sweep for all cases examined. The applicability of the intensity based PSP technique was demonstrated. The overall uncertainty in the PSP results is $5 \%$. Further studies are currently under way to explore the applicability of lifetime based PSP imaging for the simultaneous measurement of surface pressure and temperature in junction flows.

\section{Acknowledgements}

The authors would like to acknowledge the financial support of EPSRC (GR/S75680/01).

\section{References}

1. Thiede, P., and Krogmann, P.: Passive Control of Transonic Shock/ Boundary Layer Interaction, IUTAM Symposium Transonicum III (Gottingen, Germany) Springer-Verlag, Berlin (1989).

2. Bohning, R., and Jungbluth, H.: Turbulent Shock/ Boundary Layer Interaction with Control. Theory and Experiment, IUTAM Symposium Transonicum III (Gottingen, Germany) Springer-Verlag, Berlin (1989).

3. Bur, R., Corbel, B., and Delery, J.: Study of Passive Control in a Transonic Shock Wave/ BoundaryLayer Interaction. AIAA Journal 36, No. 3, (1998).

4. Raghunathan, S., and McIlwain, S.T.: Further Investigation on Transonic Shock Wave/ Boundary Layer Interaction with Passive Control. Journal of Aircraft 27, No.1, pp.60-65 (1990).

5. Gad-el-Hak, M., and Bushnell, D.M.: Separation Control: Review. J. Fluids Eng. 113, pp. 5-30 (1991)

6. Dolling, S. D.: Fifty Years of Shock-Wave/Boundary Layer Interaction Research: What Next? AIAA Journal 39, No. 8, pp. 1517-1531 (2001).

7. Panaras, A.G.: Review of the Physics of Swept-Shock/Boundary Layer Interactions. Prog. Aerospace Sci. Vol. 32, pp. 173-244, 1996.

8. Delery. M. J.: Shock Wave/ Turbulent Boundary Layer Interaction and its Control. Prog. Aerospace 
Sci. Vol. 22, pp. 209-280, 1985.

9. Barnhart, J. P., and Greber, I.: Experimental Investigation of Unsteady Shock Wave Turbulent Boundary Layer Interactions about a Blunt Fin. NASA Contractor Report 202334 (1997).

10. Hussain, S.: A study of the interaction between a glancing shock wave and a turbulent boundary layer - The effects of leading edge bluntness and sweep. Ph.D. Thesis, Cranfield University (1985).

11. Kubota, H., and Stollery, J.L.: An Experimental Study of the Interaction between a Glancing Shock Wave and a Turbulent Boundary Layer. J. Fluid Mech. 116, 431-458 (1988).

12. Squire, L.C.: Interaction of Swept and Unswept Normal Shock Waves with Boundary Layers. AIAA Journal 34, No.10, (1996).

13. Raju, C., and Viswanatha, P.R.: Application of PSP to the study of 3D Shock Boundary Layer Interaction. ICIASF '05. 21st International Congress, 197-201 (2005).

14. Chokani, N., and Squire, L.C.: Transonic Shockwave/Turbulent Boundary Layer Interactions on a Porous Surface. Aeronautical Journal 97, 163-170 (1993).

15. McConnell, A.D.: Roughness Effects on Impinging Shock Wave / Turbulent Boundary Layer Interactions. Ph.D Thesis, Churchill College Cambridge Univ. (1999).

16. Babinsky H., Inger G.R., McConnel A.D.: A basic experimental theoretical study of rough wall turbulent shock/ boundary layer interaction. 22nd International Symposium in Shock Waves, paper 0050, Imperial College, London, (1999).

17. Babinsky H., and Edwards J.A.: Large-Scale Roughness Influence on Turbulent Hypersonic Boundary Layers Approaching Compression Corners. J. Spacecraft and Rockets 34, 70-75 (1997).

18. Disimile P.J., and Scaggs N.E.: Wedge-Induced Turbulent Boundary Layer Separation on a Roughened Surface at Mach 6.0. J. Spacecraft and Rockets 28, 634-645 (1988).

19. Inger G.R.: Supersonic Shock/Turbulent Boundary Layer Interaction on a Roughened Surface. AIAA J. of Propulsion and Power 12, 463-469 (1996).

20. Holden M.S.: Studies of Boundary Layer Transition and Surface Roughness Effects in Hypersonic Flow. AFOSR Report 6430-A-5,Washington, DC (1983).

21. Merzkirch, M.: Flow Visualization. Academic Press Inc. (1987). 
22. Wong, C., Amir, M., Baudoin M., Lada, C., and Kontis, K.: Molecular Image Sensing for Pressure and Temperature Surface Mapping of Aerodynamic Flow. AIAA-04-598, 42 ${ }^{\text {nd }}$ Aerospace Sciences Meeting and Exhibit, Jan. 5-8, Reno, NV (2004).

23. Carroll, B.F., Abbitt, J.D., Lucas, E.W. and Morris, M.J.: Step Response of Pressure-Sensitive Paints. AIAA Journal 34, 521-526 (1996).

24. Sakaue, H., Matsumara, S., Schneider, S. and Sullivan, J.: Anodized Aluminium Pressure Sensitive Paint for Short Duration Testing. AIAA-02-2902, $22^{\text {nd }}$ AIAA Ground Testing Conference (2002).

25. McLahlan, B. G., Bell, J.H.: Pressure-Sensitive Paint in Aerodynamic Testing. Experimental Thermal and Fluid Science, 470-485 (1995).

26. Egami, Y., Iijima, Y., Amao, Y., Asai, K., Fuji, A., Teduka, N., and Kameda, M.: Quantitative Visualization of the leading edge vortices on delta wing by using pressure-sensitive paints. Journal of Visualization 4, No.2 (2001).

27. Bell, J.H., Schairer, E.T., Hand, L.A. and Mehta, R.D.: Surface Pressure Measurements Using Luminescence Coatings, Annual Review of Fluid Mechanics 33, 155-206 (2001).

28. Nakakita, K. and Asai, K.: Pressure-Sensitive Paint Application to a Wing-Body Model in a Hypersonic Shock Tunnel. AIAA-02-2911, 22 ${ }^{\text {nd }}$ AIAA Aerodynamic Measurement Technology and Ground Testing Conference (2002). 


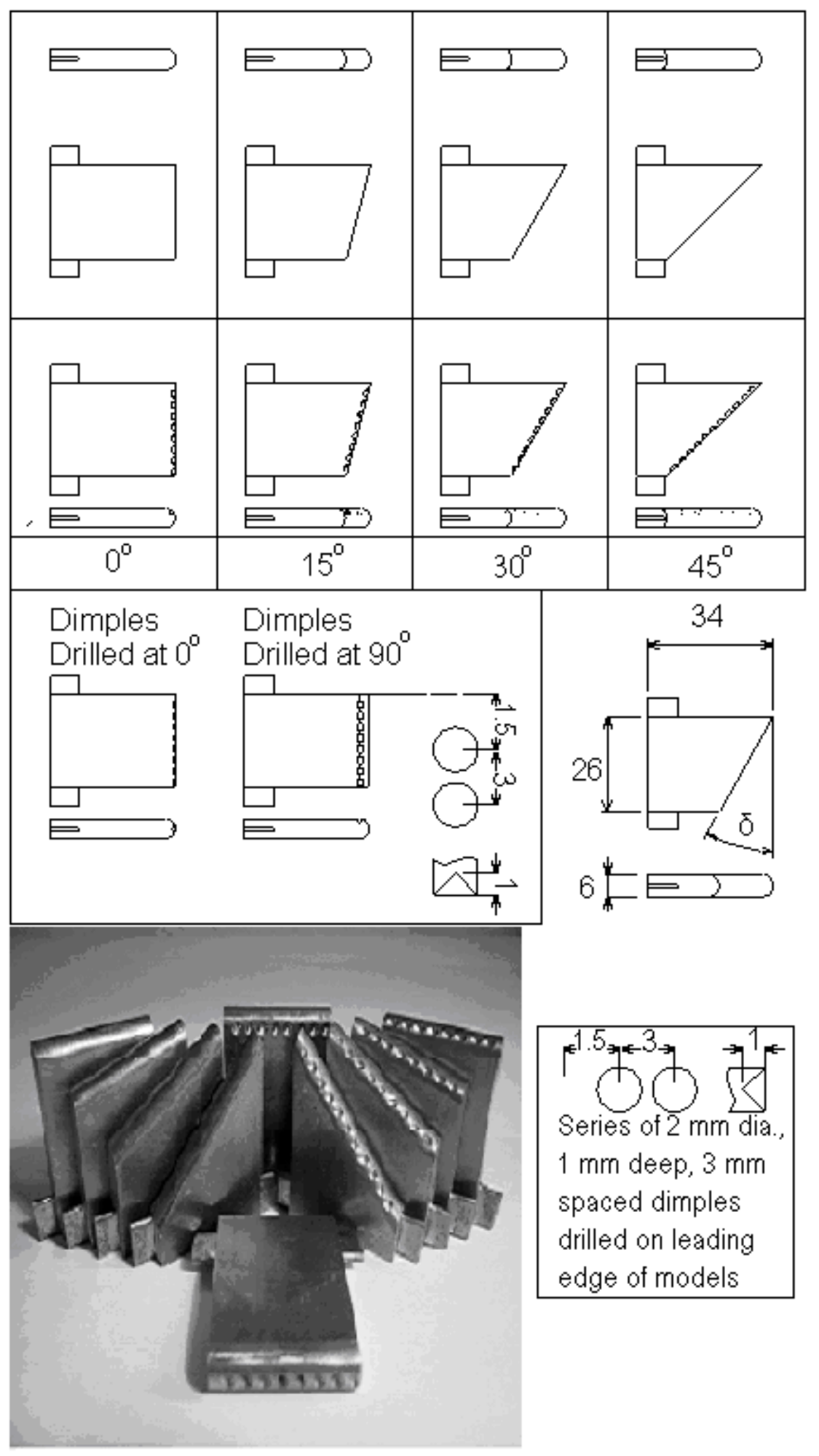

Fig. 1 Experimental models (all dimensions in $\mathrm{mm}$ ). 

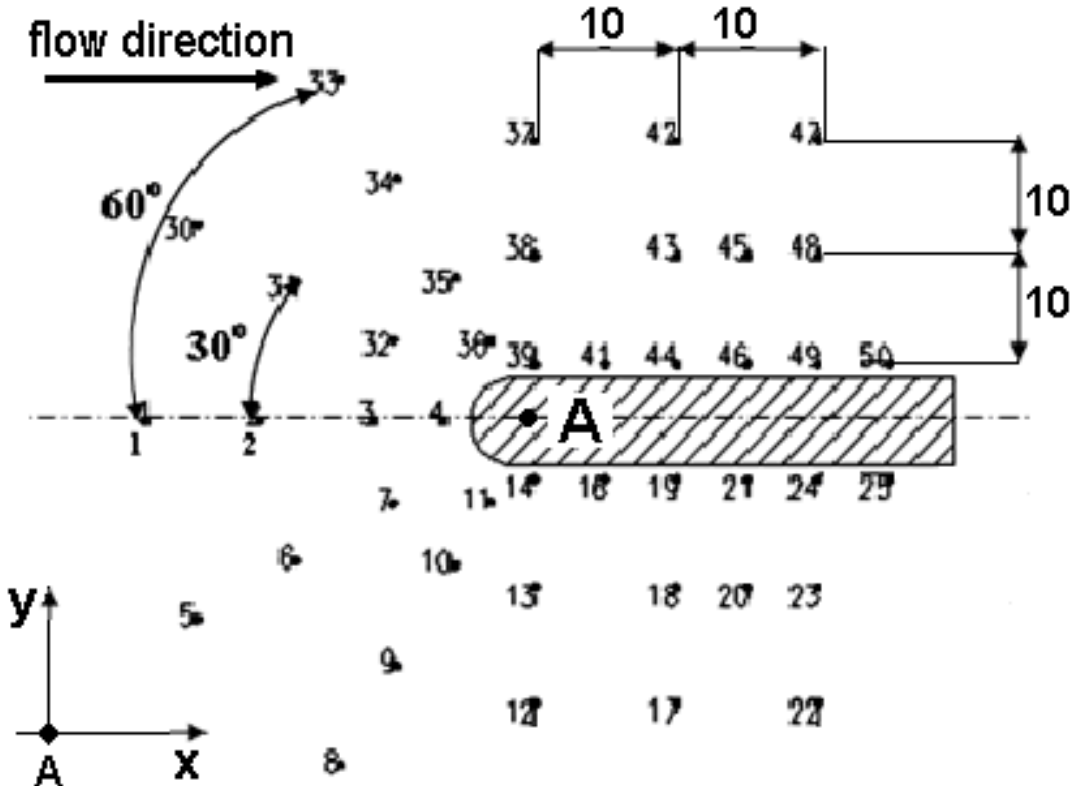

\begin{tabular}{|c|c|c|}
\hline Pressure tapping no. & $\mathrm{x}$-coordinate (in $\mathrm{mm}$ ) & $\mathrm{y}$-coordinate (in $\mathrm{mm}$ ) \\
\hline 1 & 35 & 0 \\
\hline 2 & 25 & 0 \\
\hline 3 & 15 & 0 \\
\hline 4 & 10 & 0 \\
\hline 5,30 & 30 & 19 \\
\hline 6,31 & 20 & 15 \\
\hline 7,32 & 13 & 9 \\
\hline 8,33 & 18 & 32 \\
\hline 9,34 & 13 & 22 \\
\hline 10,35 & 10 & 15 \\
\hline 11,36 & 5 & 9 \\
\hline 12,37 & 0 & 27 \\
\hline 13,38 & 0 & 17 \\
\hline 14,39 & 0 & 7 \\
\hline 15,40 & 5 & 17 \\
\hline 16,41 & 5 & 7 \\
\hline 17,42 & 10 & 27 \\
\hline 18,43 & 10 & 17 \\
\hline 19,44 & 10 & 7 \\
\hline 20,45 & 15 & 17 \\
\hline 21,46 & 15 & 7 \\
\hline 22,47 & 20 & 27 \\
\hline 23,48 & 20 & 17 \\
\hline 24,49 & 20 & 7 \\
\hline 25,50 & 25 & 7 \\
\hline
\end{tabular}

Fig. 2 Location of pressure tappings. Note: The origin of the $x-y$ coordinate system is at point A located at the centre of the hemi-cylindrical leading edge on the line of symmetry of the models. 


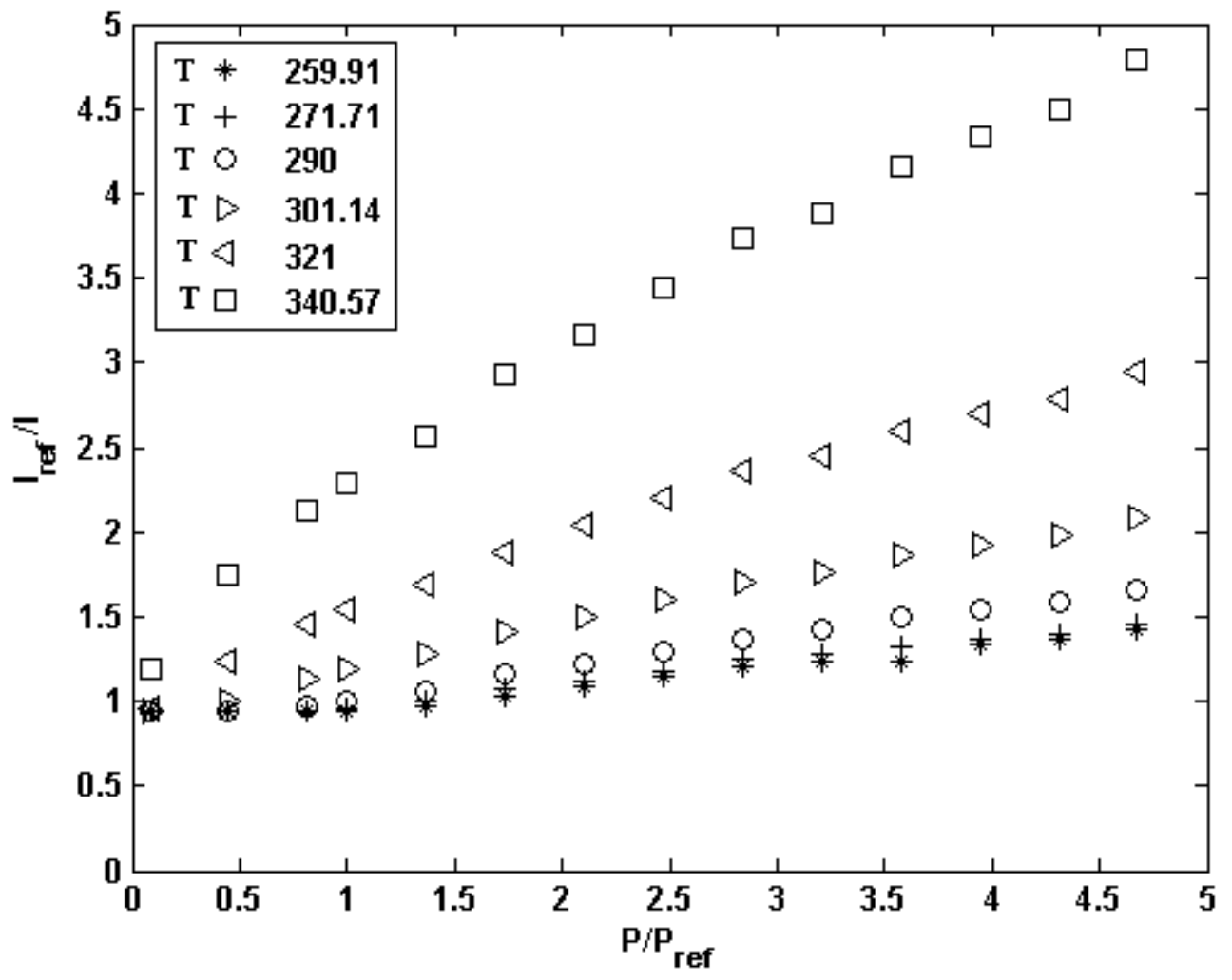

Fig. 3 PSP calibration curves. 


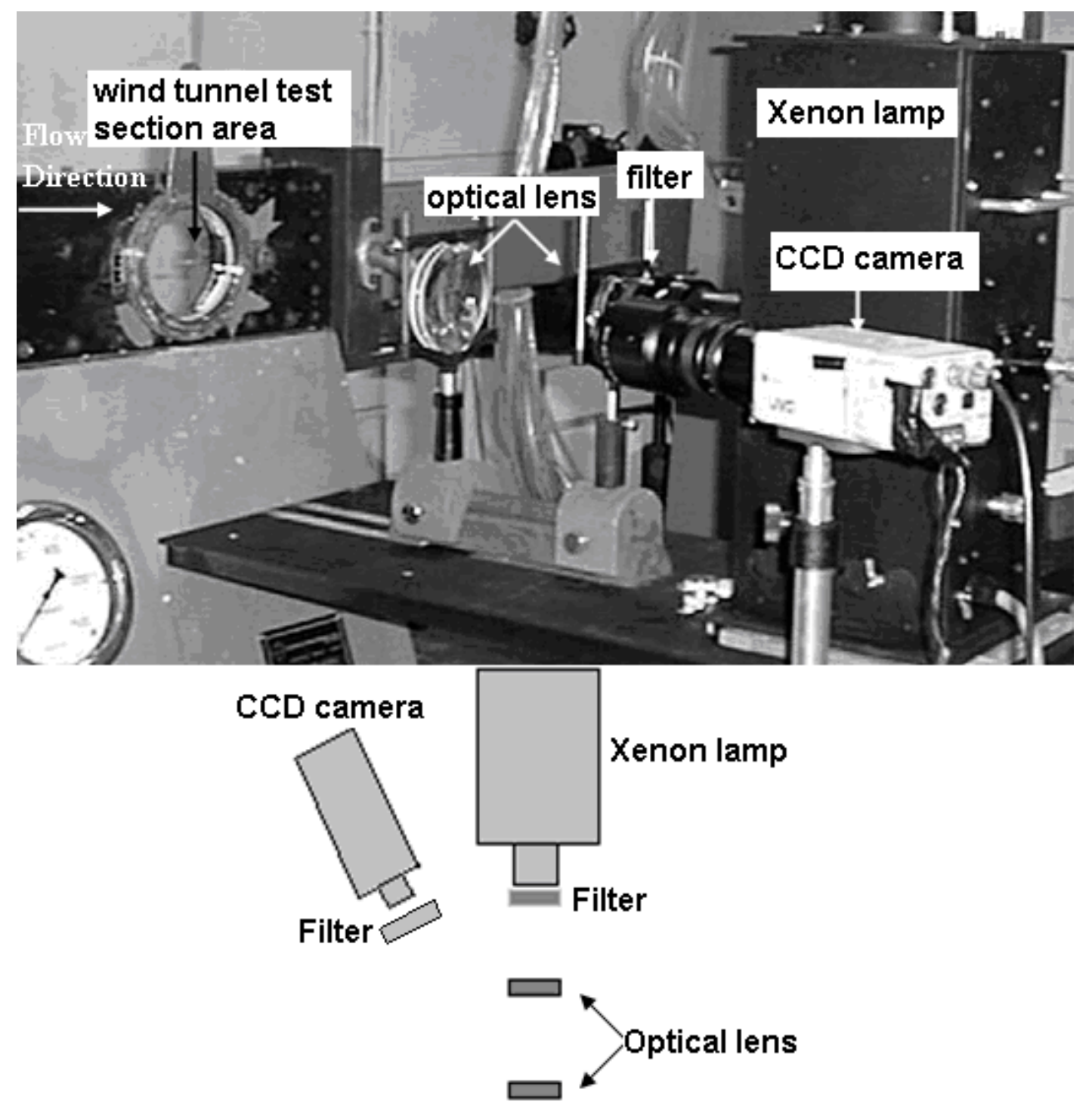

Flow direction Fin model

\begin{tabular}{|c|c|}
\hline Wind Tunnel & Wind Tunnel \\
\hline
\end{tabular}

wind tunnel test section

Fig. 4 Schematic of the PSP optical set-up. 

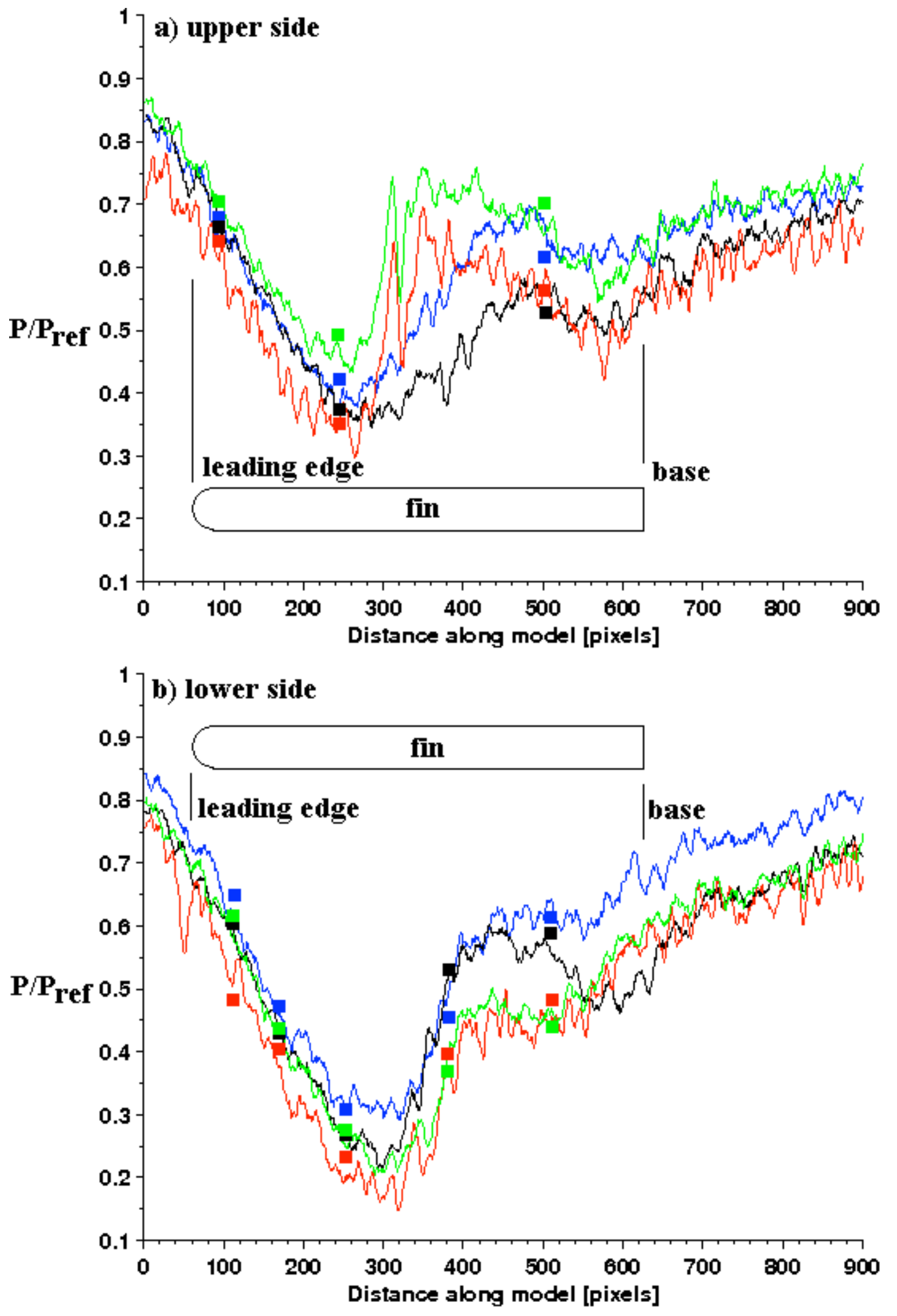

— PSP, no-dimples PSP, dimples at 0 deg. PSP, dimples at 45 deg. PSP, dimples at 90 deg. $\square$ tapping, no-dimples $\square$ tapping, dimples at 0 deg.

a tapping, dimples at $45 \mathrm{deg}$. - tapping, dimples at $90 \mathrm{deg}$.

Fig. 5 Comparisons in the stream-wise direction of PSP results with the discrete measurements of pressure tappings located in no. 13,17, 18, 20, 23 (lower side) 37, 42, 47 (upper side); $\mathrm{M}=0.8,0^{\circ}$ sweep. 


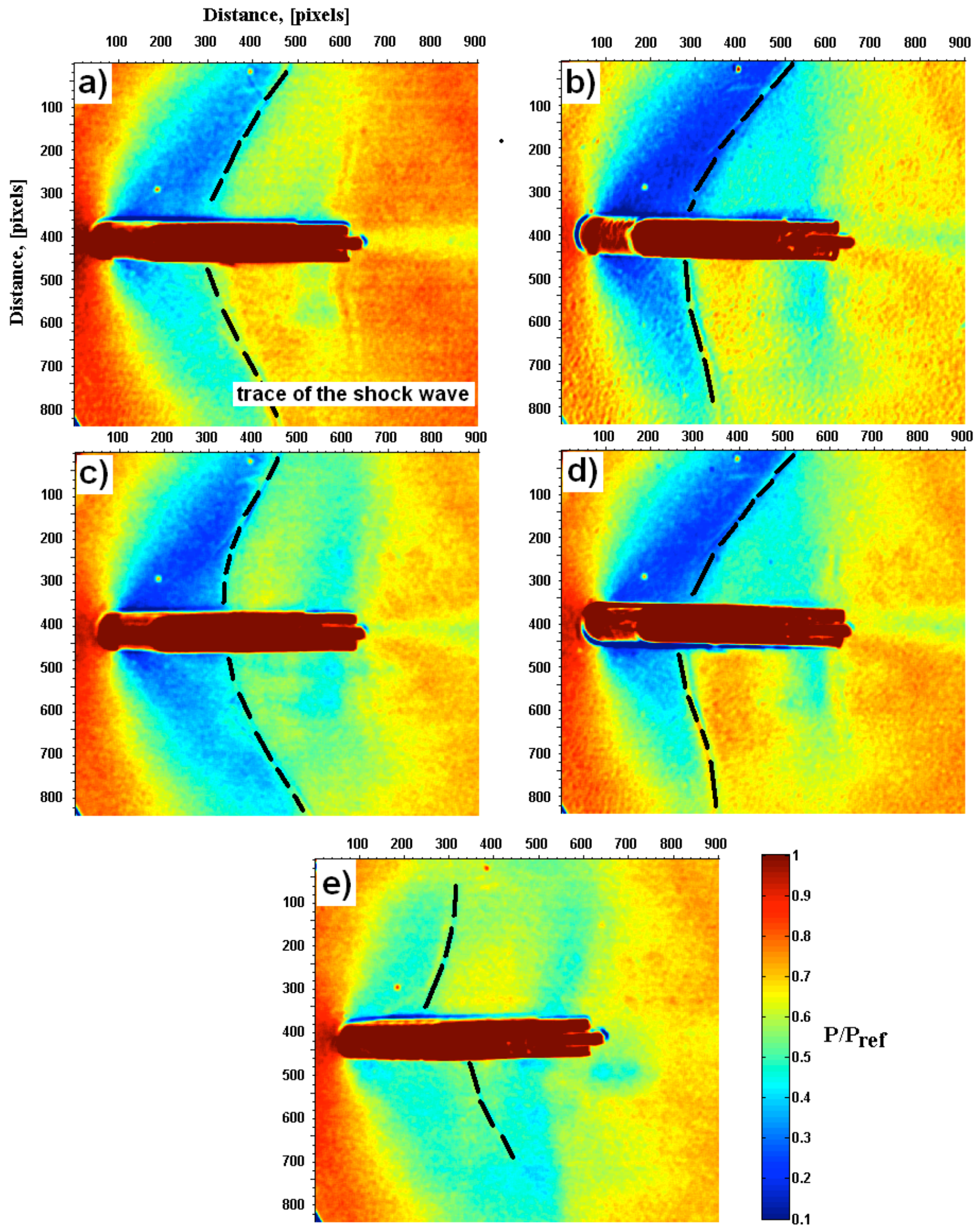

Fig. 6 PSP results at $\mathrm{M}=0.8$; a) no-dimples case, $\left(0^{\circ}\right.$ sweep $)$; b) dimples at $45^{\circ},\left(0^{\circ}\right.$ sweep $)$; c) dimples at $0^{\circ},\left(0^{\circ}\right.$ sweep $)$; d) dimples at $90^{\circ},\left(0^{\circ}\right.$ sweep $)$; e) dimples at $45^{\circ},\left(15^{\circ}\right.$ sweep $)$. 

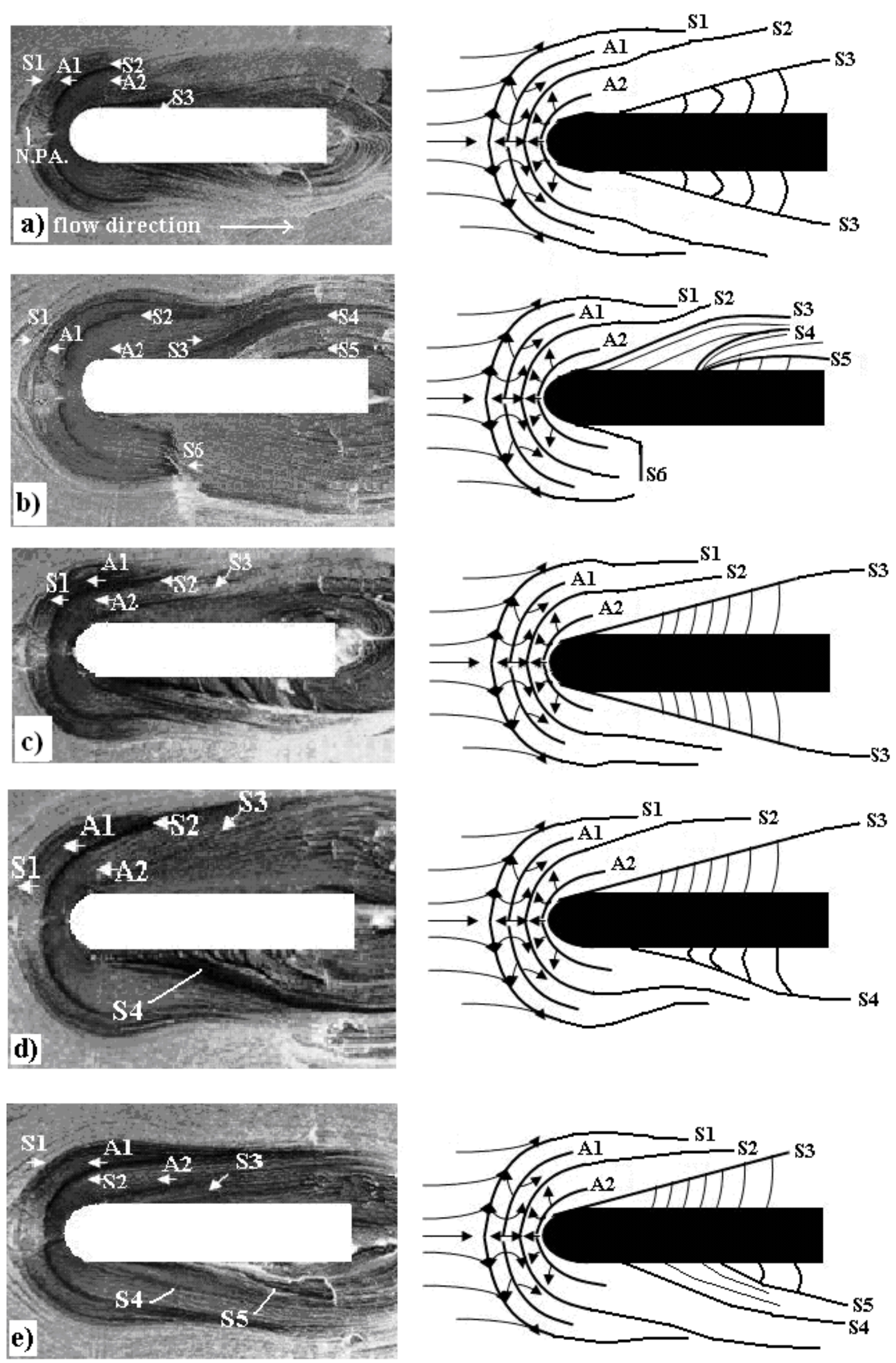

Fig. 7 Surface flow topology at $M=0.8$; a) no-dimples case, $\left(0^{\circ}\right.$ sweep $)$; b) dimples at $45^{\circ}$, ( $\left(0^{\circ}\right.$ sweep $)$; c) dimples at $0^{\circ},\left(0^{\circ}\right.$ sweep $)$; d) dimples at $90^{\circ},\left(0^{\circ}\right.$ sweep $)$; e) dimples at $45^{\circ},\left(15^{\circ}\right.$ sweep $)$. 


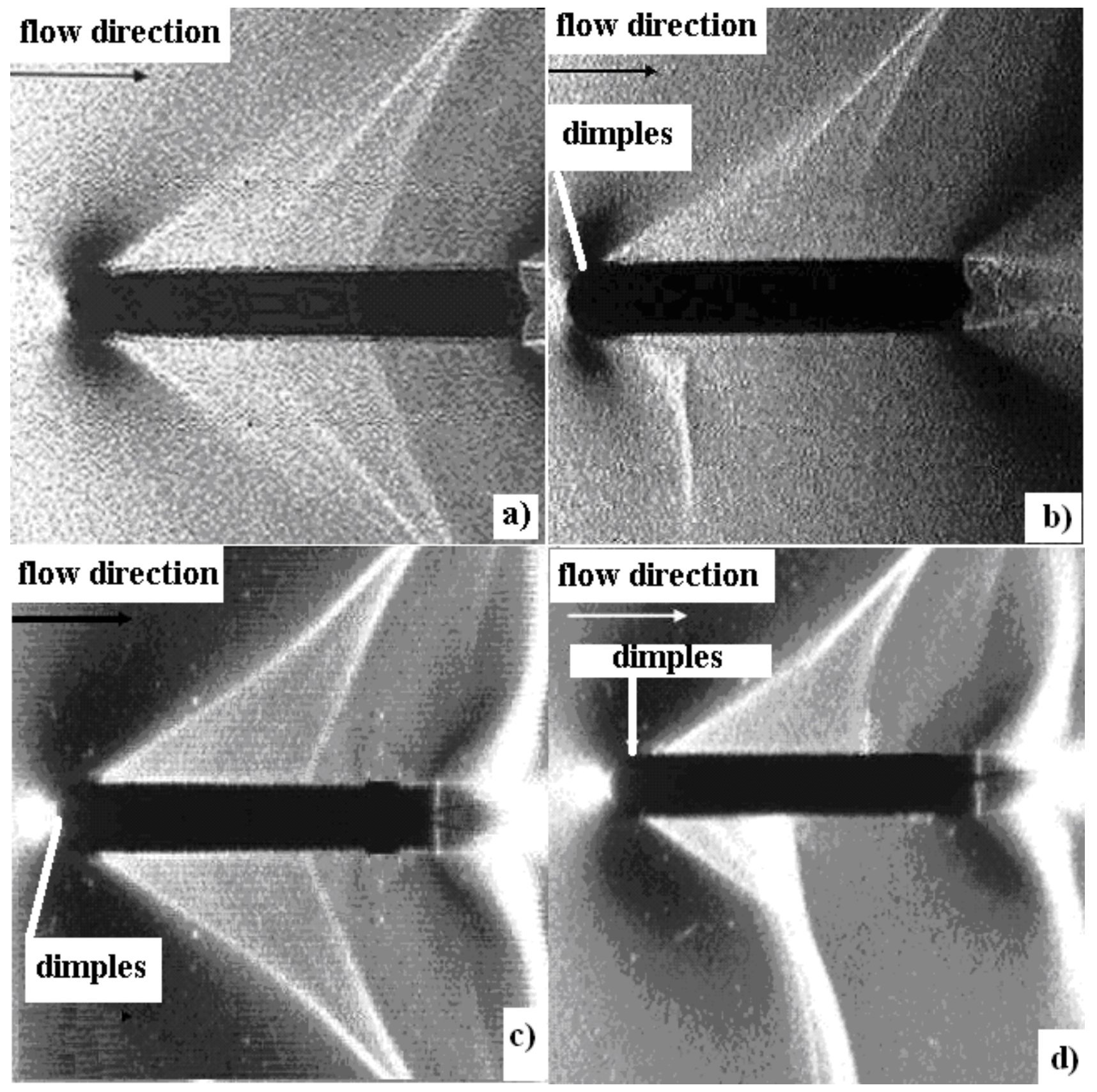

Fig. 8 Schlieren pictures at $\mathrm{M}=0.8$ for the $0^{\circ}$ sweep case; a) no-dimples; b) dimples at $45^{\circ}$; c) dimples at $0^{\circ} ;$ d) dimples at $90^{\circ}$. 


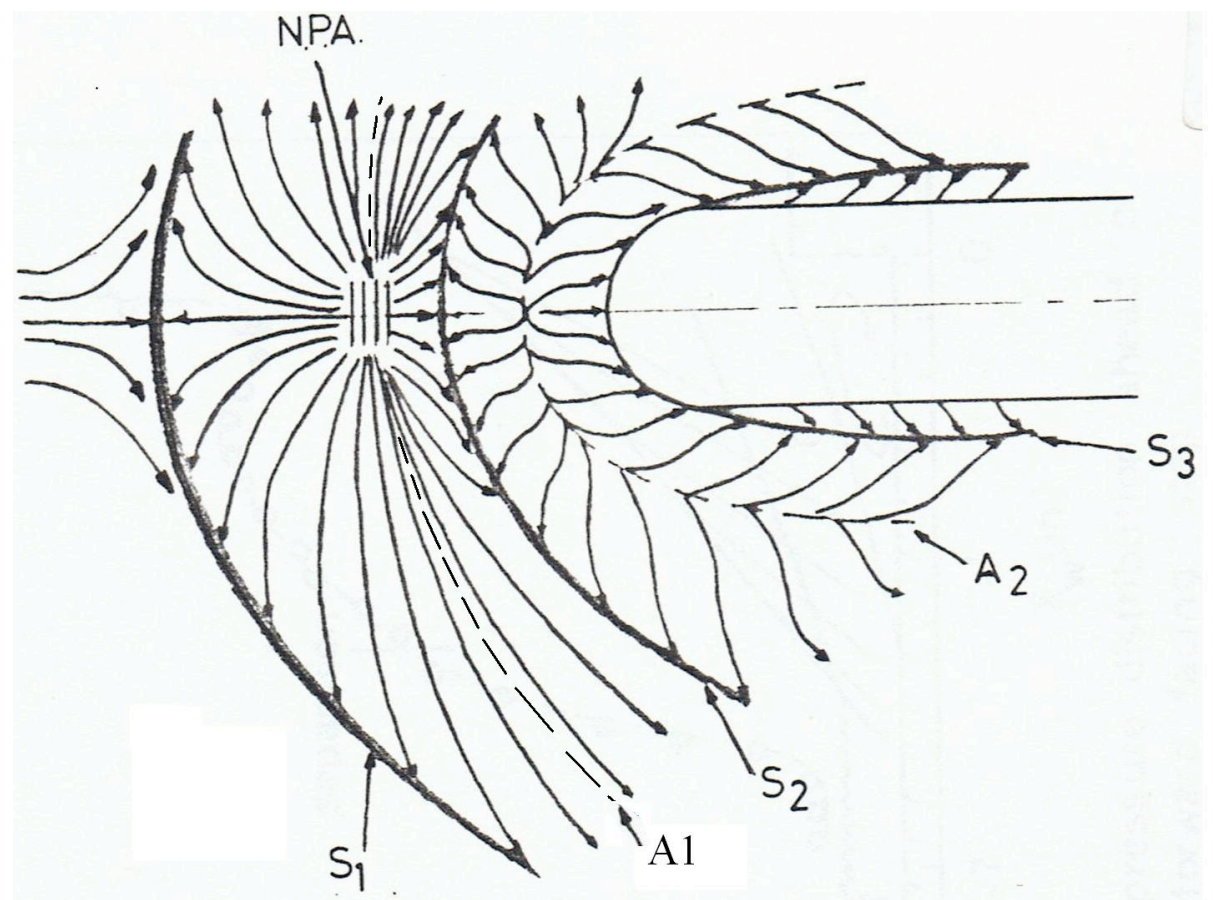

a) Surface streak pattern

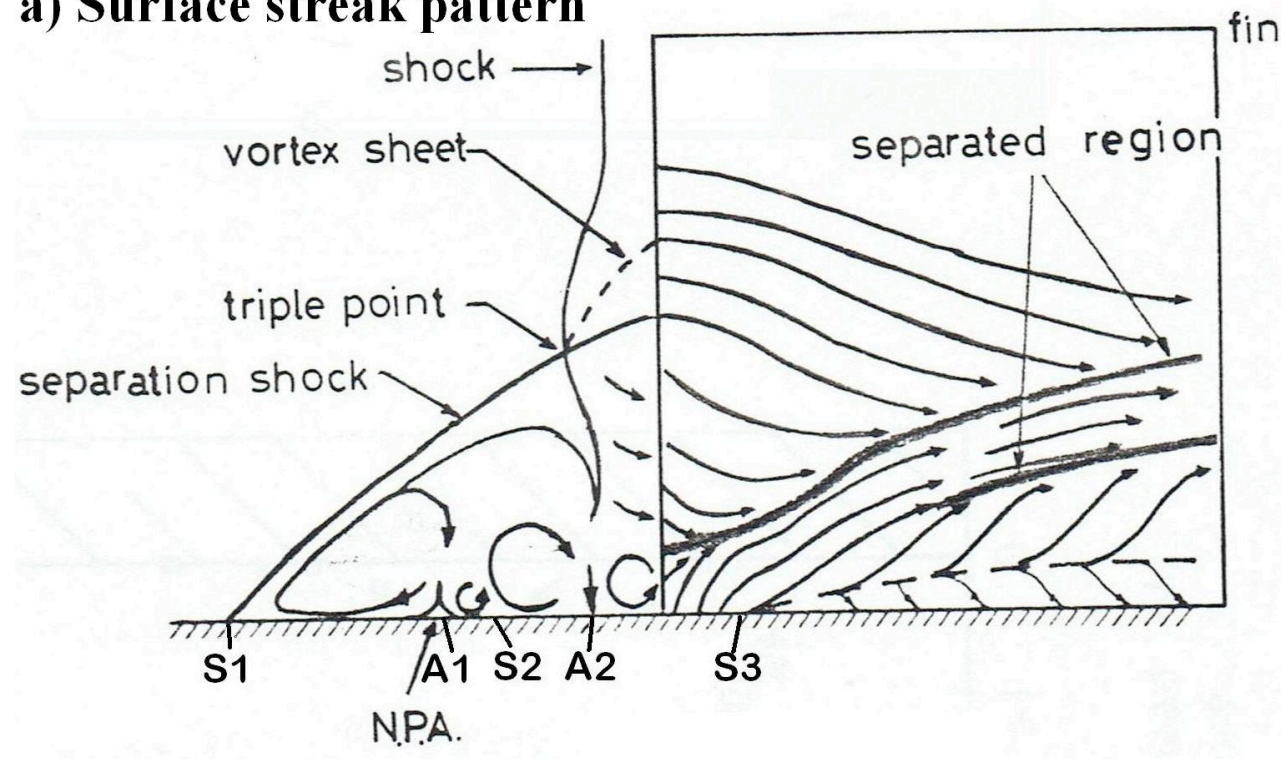

\section{b) Flow field model}

Fig. 9 Schematic of the observed surface streak pattern and flow field based on Hussain's model [10] for unswept blunt fin 


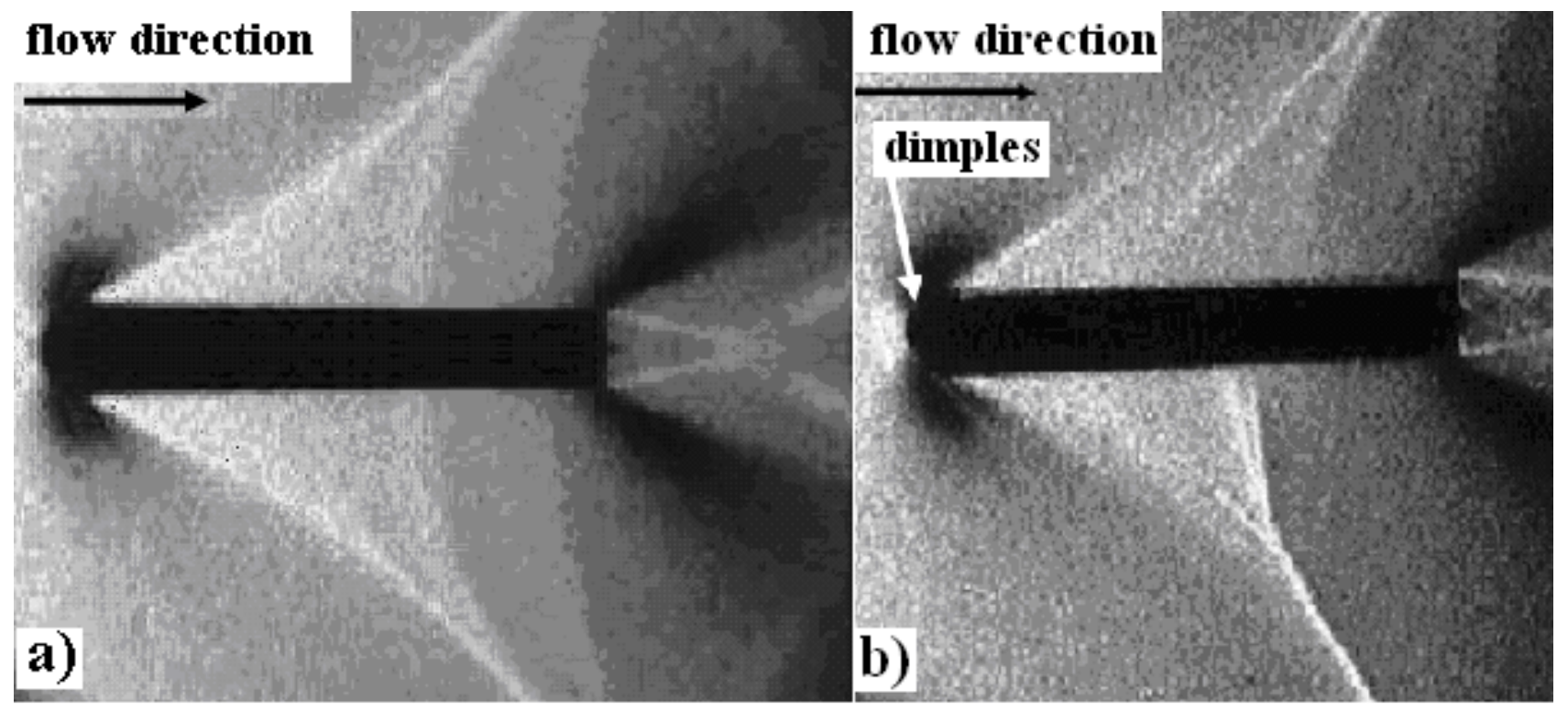

Fig. 10 Schlieren pictures at $M=1.4$ for the $0^{\circ}$ sweep case; a) no dimples; b) dimples at $45^{\circ}$. 

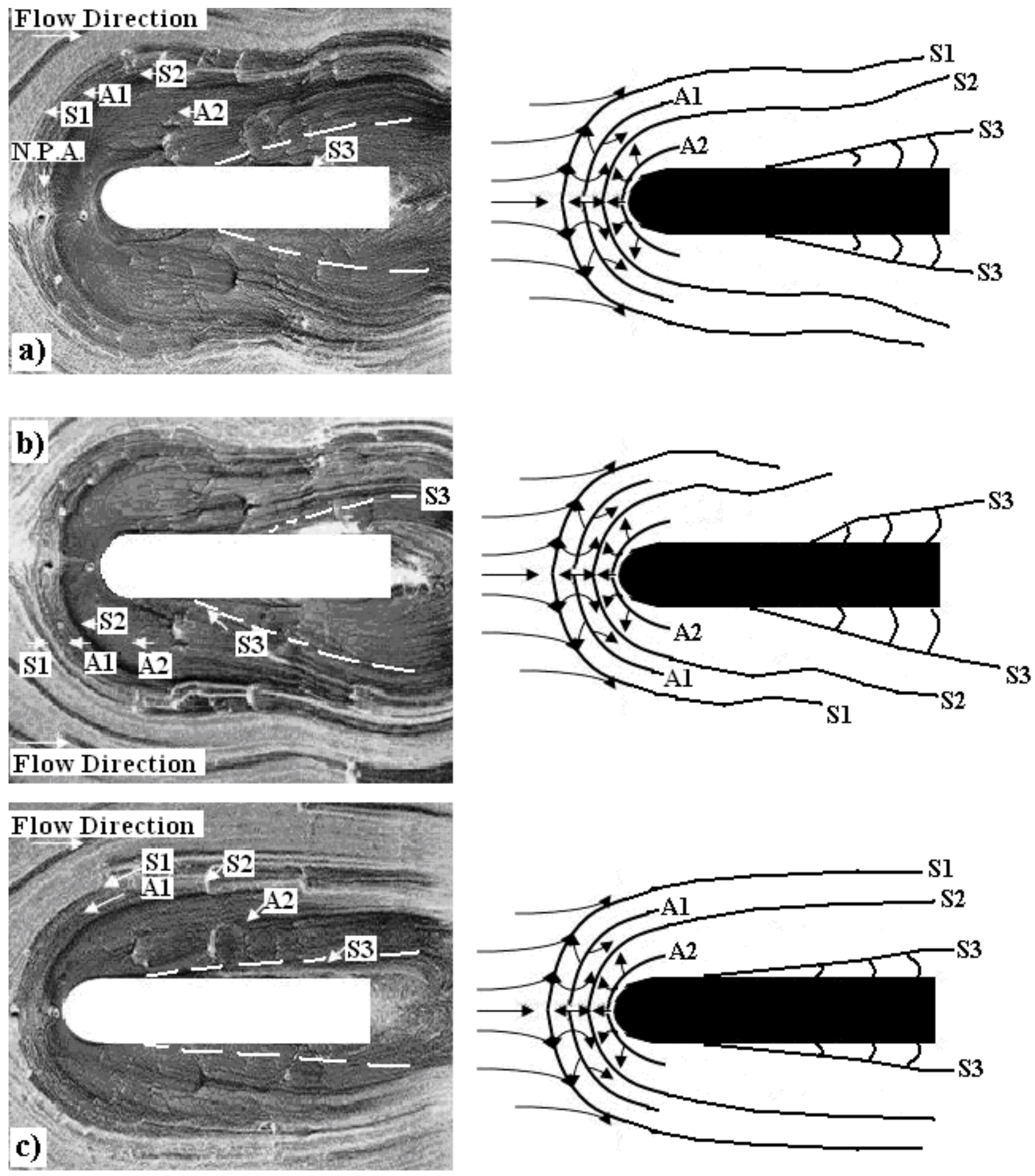

Fig. 11 Surface flow topology at $M=1.4$; a) no-dimples case, $\left(0^{\circ}\right.$ sweep $)$; b) dimples at $45^{\circ},\left(0^{\circ}\right.$ sweep $)$; c) no-dimples, $\left(30^{\circ}\right.$ sweep $)$. 


\section{Flow direction}

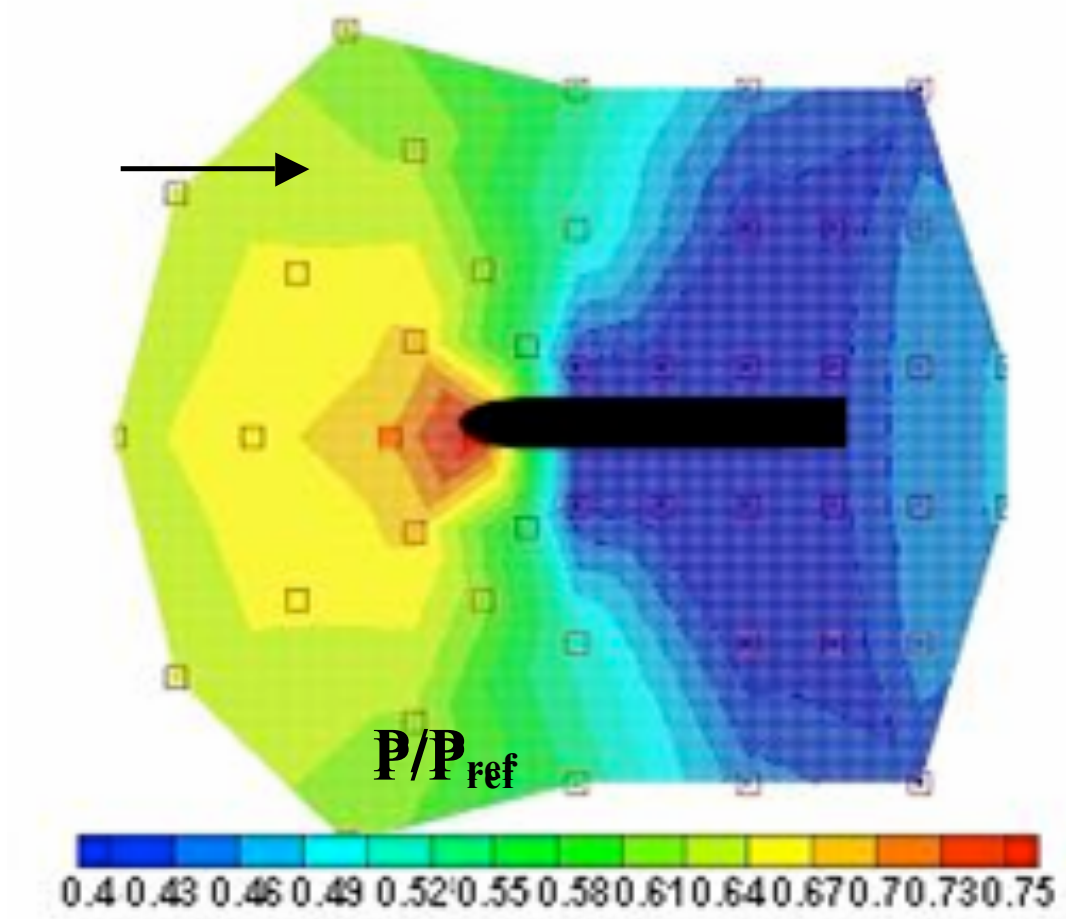

a)

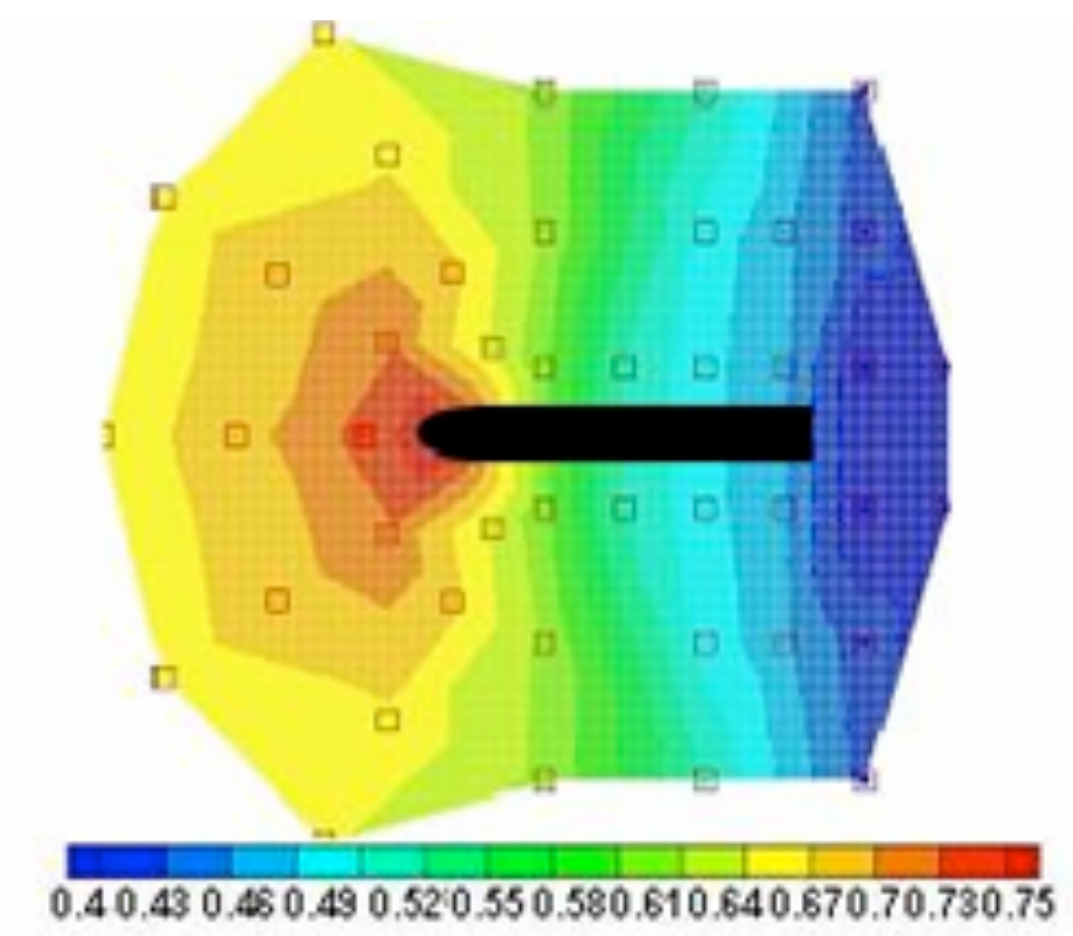

b)

Fig. 12 Pressure maps of the transducer data for the no-dimples case at $\mathrm{M}=1.4$; a) $0^{\circ}$ sweep; b) $30^{\circ}$ sweep. 